\title{
Pelatihan Menyusun Proposal Bisnis dan Komunikasi Efektif dalam Presentasi Proposal pada Kelompok Karang Taruna di Balekambang Jakarta Timur
}

\author{
Kanaria Herwati ${ }^{1}$, Indra Suyahya ${ }^{2}$ \\ Universitas Indraprasta PGRI \\ kanaria_smart@yahoo.com ${ }^{1}$, indrasuyahya@gmail.com ${ }^{2}$
}

\begin{abstract}
Abstrak
Kegiatan pengabdian masyarakat ini bertujuan untuk memberikan pelatihan pembuatan proposal bisnis yang baik, benar, dan menarik serta membangun kemampuan berkomunikasi dalam mempresentasikan bisnis pada Kelompok Karang Taruna Rt. 003/ 05 Kel. Balekambang, Condet Jakarta Timur. Target rencana kegiatan ini adalah salah satu dari tridarma perguruan tinggi yaitu pengabdian kepada masyarakat. Metode yang digunakan oleh Tim Dosen Universitas Indraprasta PGRI dalam kegiatan pengabdian masyarakat ini adalah dengan memberikan pelatihan penyusunan proposal bisnis dan cara mempresentasikannya kepada 30 (tiga puluh) remaja yang bermukim di Jalan Kayumanis Gang AMD 28 RT 003 RW 05 Condet Balekambang, Kramat Jati, Jakarta Timur.
\end{abstract}

Kata Kunci: proposal bisnis, komunikasi, presentasi

\section{Training on Preparing Business Proposals and Effective Communication in Proposal Presentations to Karang Taruna Balekambang, East Jakarta}

\begin{abstract}
Activities of Community devotion aims to provide the training of the establishment of good business proposal, correct, and interesting and build a welcome to communicate in the present business to the group of corals Taruna Rt. 003/05 Kel. Balekambang, East Jakarta Condet. The Target plan of this activity is one of the Tri Dharma colleges, namely community service. The method used by the University of Indraprasta PGRI Lecturer in the activities of the Community is to give the training in drafting business proposal and how to present it to 30 (thirty) teenagers residing on Jl. Kayumanis Gg. AMD 28 Rt. 003 Rw. 05 Condet Balekambang, Kramat Jati, East Jakarta.
\end{abstract}

Keywords: Business proposal, communication, presentation

\section{PENDAHULUAN}

Dalam membangun suatu bisnis, baik bisnis tersebut dalam tingkat yang kecil, menengah bahkan sampai kepada bisnis yang besar sekalipun, tentunya membutuhkan modal baik modal awal ataupun modal untuk kelangsungan usaha. Namun modal bukan merupakan faktor utama dalam sebuah bisnis walaupun pada kenyataannya modal merupakan suatu kekuatan agar bisnis dapat bertahan atau bahkan mampu membuat bisnis menjadi berkembang.

Fokus permasalahan utama dari para pelaku usaha mikro kecil menengah (UMKM) adalah dalam pemasaran (Chrismardani et al., 2014). Proses pemasaran merupakan proses terpenting untuk menyebarkan produk dari produsen sampai ke tangan konsumen. Inti dari berlangsungnya sebuah usaha adalah ketika kita dapat menyusun strategi pemasaran yang 
baik. Memiliki produk berkualitas tinggi saja tidak cukup untuk berkecimpung dalam dunia wirausaha, tetapi memiliki strategi pemasaran yang baik dapat menentukan keberhasilan sebuah usaha (Isnaini, 2009).

Kendala yang sering dihadapi oleh seorang yang berwirausaha adalah ketika hendak mengembangkan usahanya namun hanya memiliki modal yang terbatas atau malah justru kekurangan modal, solusi yang biasanya dipilih adalah mengajukan pinjaman ke bank atau memberikan tawaran kerja sama dengan para investor. Dalam menjalin kerja sama tersebut tentunya perlu mempersiapkan proposal bisnis dan membekali diri dengan kemampuan berkomunikasi dalam mempresentasikan bisnis di hadapan para calon investor. Tidak mudah untuk meyakinkan investor atau pihak bank terhadap usaha kita. Bukan hanya dibutuhkan proposal bisnis dan laporan keuangan yang baik, tetapi cara kita mempresentasikan bisnis kita menjadi kunci keberhasilannya. Pada akhirnya tidak sedikit yang lebih memilih menambahkan modal mereka melalui peminjaman dana pada rentenir yang akhirnya mengakibatkan bukan usaha yang berkembang yang mereka dapatkan tetapi kejatuhan, karena harus membayar bunga pinjaman dari rentenir yang tinggi.

Seperti yang telah dijelaskan di atas, maka kami sebagai tim pelaksana pengabdian masyarakat melirik kelompok Karang Taruna di Kelurahan Balekambang, yang beranggotakan pemuda-pemudi yang aktif dan kreatif. Salah satu alasan pemilihan lokasi didasarkan pada letak Kelurahan Balekambang yang hanya berjarak 2,5 km dari Universitas Indraprasta PGRI Kampus B. Kelurahan Balekambang sendiri terdiri dari $5 \mathrm{RW}$, dengan 53 RT. Kelima RW tersebut memiliki kelompok Karang Taruna dan terdapat aktivitas setiap minggunya. Melihat keaktifan dari kelompok Karang Taruna tersebut maka tim pelaksana pengabdian terhadap masyarakat berusaha untuk memberikan pelatihan untuk menambah pengetahuan dalam menyusun proposal bisnis yang baik dan benar serta pembekalan keterampilan berkomunikasi dalam mempresentasikan bisnis di kelompok tersebut.

Melihat keaktifan dan potensi dari kelompok remaja di lingkungan Kelurahan Balekambang, khususnya Karang Taruna RW 03 dan 04, maka tim pelaksana pengabdian masyarakat tertarik untuk memberikan pelatihan penyusunan proposal bisnis yang baik, benar, dan menaik serta membangun kemampuan berkomunikasi untuk mempresentasikan bisnisnya.

Seperti yang dikemukakan (Moh. Alifuddin dan Mashur Razak, 2015:46) bisnis adalah sesuatu yang menyenangkan. Bisnis merupakan permainan yang segar dan menumbuhkan rasa percaya. Dunia bisnis, apa pun jenis usahanya, perlu. Mengapa? Karena kita ingin menciptakan unit bisnis yang memberikan peluang kepada setiap orang untuk ikut berjuang mencari uang. Dengan keterbukaan, semua ikut berpikir dan bertindak seperti pemilik, bukan sekedar sebagai orang yang digaji. Itu pun model usaha yang mungkin dapat diterapkan saat ini, ketika perekonomian Indonesia tidak mengalami perbaikan yang signifikan dan dihadapkan pada persaingan global yang sangat masif.

Beberapa permasalahan yang dihadapi oleh kelompok Karang Taruna di antaranya adalah:

1. Kurangnya pengetahuan dan pemahaman tentang bagaimana cara mengorganisasikan usaha kecil yang sudah berjalan saat ini dengan baik sehingga penghasilan yang didapat belum maksimal.

2. Kurangnya pengetahuan anggota kelompok karang taruna dalam membuat dan menyusun proposal bisnis yang baik, benar, dan menarik. 
Vol. 1, No. 3,

November

2020

pp. $100-106$

e-ISSN:

2722-2004

Title

Training on

Preparing

Business

Proposals and

Effective

Communication

in Proposal

Presentations to

Karang Taruna

Balekambang,

East Jakarta

\section{Author}

K. Herwati,

I. Suyahya

3. Minimnya keberanian dan kemampuan berkomunikasi dalam mempresentasikan bisnis yang dimiliki baik di hadapan stakeholder, perbankan ataupun para investor.

Untuk mengatasi permasalahan yang telah disebutkan pada pendahuluan, maka solusi yang ditawarkan dalam pengabdian masyarakat ini adalah mengembangkan dan meningkatkan kemampuan Kelompok Karang taruna dalam membuat suatu proposal bisnis dan membangun kemampuan berkomunikasi dalam mempresentasikan bisnisnya baik di hadapan para stakeholder, perbankan, dan tentunya di hadapan investor dengan harapan bisnis yang sudah berjalan dapat terus berkembang dan meningkat.

\section{METODE PELAKSANAAN}

Kegiatan pengabdian masyarakat ini dimulai dengan mengurus perizinan dan peninjauan daerah mitra yang dilakukan pada Februari 2020. Sementara pelaksanaan kegiatan pengabdian masyarakat dilakukan pada Agustus 2020. Tempat kegiatan pengabdian masyarakat ini di Kantor Kelurahan Balekambang, yang beralamat Jl. Pucung No.92, RT.9/RW.2, Balekambang, Kramatjati, Kota Jakarta Timur, Daerah Khusus Ibukota Jakarta 13530.

\section{HASIL DAN PEMBAHASAN}

Mitra pengabdian masyarakat yang menjadi objek dalam kegiatan pelatihan penyusunan proposal bisnis yang benar dan menarik serta melatih kemampuan presentasi bisnis adalah kelompok Karang Taruna beranggotakan pemuda-pemudi di lingkungan Kelurahan Balekambang, khususnya Karang Taruna RW 03 dan 04.

Kondisi pandemik Corona dan tim abdimas harus mematuhi peraturan PSBB yang berlaku, maka jumlah kelompok karang taruna yang berpartisipasi dalam kegiatan pelatihan ini terpaksa dibatasi sejumlah 20 orang. Adapun latar belakang usia dan pendidikan para peserta antara lain usia 16-21 tahun, pendidikan SMA/sederajat, mahasiswa, ataupun karyawan.

Tabel 1. Data Peserta Pengabdian Masyarakat

\begin{tabular}{clcc}
\hline \multicolumn{1}{c}{ Timestamp } & \multicolumn{1}{c}{ Nama } & Usia & Pekerjaan \\
\hline 8/2/2020 8:29:47 & Ahmad Ibnu Islami & 19 & Mahasiswa \\
8/2/2020 8:30:14 & Muhammad Rafqi & 21 & Mahasiswa \\
8/2/2020 8:30:16 & Rifkiyah Fadilah & 18 & Mahasiswi/pelajar \\
8/2/2020 8:32:14 & Cantikafitrirayani & 17 & Kuliah \\
8/2/2020 8:32:27 & Citra Aisyah Musfiani & 18 & Fresh graduate \\
8/2/2020 8:33:28 & Nadia Nurul Hikmah & 20 & Mahasiswa \\
8/2/2020 8:34:33 & Rayhan Akmal Juniasto & 19 & Pelajar \\
8/2/2020 8:39:33 & Sri Mulyani & 22 & Mahasiswa \\
8/2/2020 8:39:49 & Liza Agustian Falaila & 20 & Mahasiswa \\
8/2/2020 8:47:40 & Muhammad Azmi Zen & 18 & Belum bekerja \\
8/2/2020 8:48:44 & Alfi Rahmaniah & 21 & Mahasiswa \\
8/2/2020 9:21:08 & Muhamad Nofel & 22 & mahasiswa \\
\hline
\end{tabular}


KANGMAS: Karya Ilmiah Pengabdian Masyarakat, 1 (3), November 2020 - 103 http://journal.neolectura.com/index.php/Kangmas

\begin{tabular}{cllc}
\cline { 2 - 4 } 8/2/2020 9:28:42 & Ihza Dharmawan Mohammad & 21 & Karyawan swasta \\
8/2/2020 9:41:09 & Muhamad Ardiyansyah & 16 & Pelajar \\
$8 / 2 / 2020$ 9:53:44 & Nida Hamidah & 19 & Tidak bekerja \\
8/2/2020 10:44:17 & Tunas Deri Pratama & 22 & Mahasiswa \\
$8 / 2 / 2020$ 10:52:08 & Liza Agustian Falaila & 20 & Mahasiswa \\
$8 / 2 / 2020$ 10:53:10 & Ahmad Yani & 21 & Karyawan swasta \\
\hline
\end{tabular}

Sumber: Data Pengabdian Masyarakat (2020)

Berikut adalah dokumentasi kegiatan abdimas dengan menggunakan aplikasi Zoom.

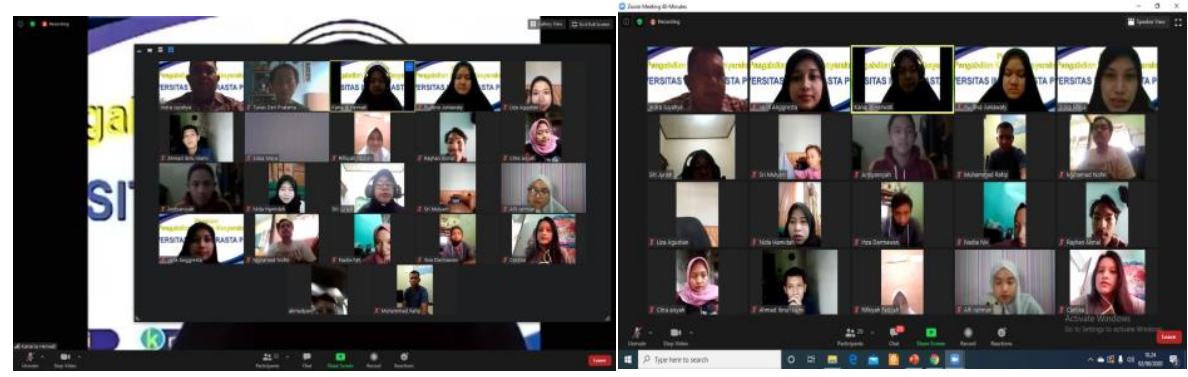

Gambar 1. Peserta mengikuti pelatihan melalui aplikasi Zoom

Berdasarkan pelaksanaan pengabdian masyarakat yang dilaksanakan dalam masa pandemik Corona ini, pelaksanaan abdimas dilakukan secara daring dengan menggunakan aplikasi Zoom. Kendala yang dihadapi adalah koneksi yang tidak stabil sehingga membuat penyampaian materi menjadi kurang maksimal. Akan tetapi hal tersebut tidak mengurangi semangat tim abdimas untuk menyampaikan materi. Begitu juga dengan peserta yang terlihat antusias dan bersemangat menyimak pemaparan materi yang diberikan. Akhirnya, materi pelatihan penyusunan proposal bisnis yang baik dan membangun rasa percaya diri dalam mempresentasikan proposal dapat tersampaikan dan diterima dengan baik.

Business plan merupakan suatu dokumen yang menyatakan keyakinan akan kemampuan sebuah bisnis untuk menjual barang atau jasa dengan menghasilkan keuntungan yang memuaskan dan menarik bagi penyandang dana.

Membuka usaha baru tidak mungkin tanpa ada rencana sebelumnya. Rencana harus ada betapa pun sederhananya secara tertulis. Namun, wirausaha baru di negara kita banyak yang tidak mau ataupun mungkin tidak mampu atau segan menulis rencana tertulis tersebut karena berbagai alasan.

Perencanaan yang tidak tertulis pasti sudah ada rekayasa dalam pikiran, yaitu suatu rekayasa secara sederhana tentang jawaban dari berbagai pernyataan antara lain, usaha apa yang akan dibuka, mengapa memilih usaha tersebut, di mana lokasinya, siapa konsumennya, dari mana sumber modal dsb. Tampaknya wirausaha baru seperti ini cenderung melaksanakan kegiatan trial and error atau coba-coba. Seandainya gagal, mereka akan beralih ke usaha yang lain. Model seperti ini banyak dijumpai dalam masyarakat bisnis kita. Dinyatakan oleh David H. Bangs Jr bahwa seorang pengusaha yang tidak bisa membuat perencanaan sebenarnya merencanakan kegagalan. 
Business plan itu sendiri berisi 1) Pendahuluan, yang terdiri atas nama dan

Vol. 1, No. 3,

November

2020

pp. $100-106$

e-ISSN:

2722-2004

Title

Training on

Preparing

Business

Proposals and

Effective

Communication

in Proposal

Presentations to

Karang Taruna

Balekambang,

East Jakarta

Author

K. Herwati,

I. Suyahya alamat perusahaan, nama dan alamat pemilik, serta nama dan alamat penanggung jawab yang bisa dihubungi sewaktu-waktu; 2) Rangkuman eksklusif lebih kurang tiga halaman yang menjelaskan secara komplit isi business plan; 3) Analisis industri, yang berisi perspektif masa depan industri, analisis persaingan, segmentasi pasar yang dimasuki, ramalan-ramalan tentang produk yang dihasilkan; 4) Deskripsi tentang usaha, yang menjelaskan produk yang dihasilkan, jasa pelayanan, ruang lingkup bisnis, personalia dan perlengkapan kantor, serta latar belakang identitas pengusaha; 5) Rencana produksi, berisi tentang proses pabrikasi, keadaan gedung dan perlengkapannya, keadaan mesin dan perlengkapannya, serta sumber-sumber bahan baku; 6) Rencana pemasaran, terdiri atas penetapan harga, pelaksanaan distribusi, promosi yang dilakukan, juga pengembangan produk; 7) Perencanaan organisasi yang menjelaskan bentuk kepemilikan dan struktur organisasi seperti informasi tentang partner, uraian tentang kekuasaan, latar belakang anggota tim manajemen, serta peranan dan tanggung jawab personalia juga organisasi; 8) Risiko, yang menjelaskan evaluasi tentang kelemahan bisnis serta gambaran teknologi; 9) Perencanaan permodalan yang memuat neraca permulaan perusahaan seperti proyeksi aliran kas, analisa titik impas, juga sumber-sumber permodalan; 10) Apendiks, yang berisi suratsurat, data penelitian pasar, surat-surat kontrak dan dokumen perjanjian lainnya, serta daftar harga dari pemasok barang.

Sedangkan cara mempresentasikan proposal bisnis yang menarik bagi pihak investor, antara lain: 1) Elevator Pitch, dalam dunia bisnis dikenal istilah elevator pitch yakni pembicaraan singkat kurang dari 1 menit di dalam lift; 2) The Problem, setiap presentasi proposal usaha haruslah menjelaskan apa permasalahan yang terjadi. Apa problem yang ingin Anda selesaikan? 3) The Solution, setelah Anda menjelaskan permasalahan, sekarang tiba saatnya menjelaskan solusi yang Anda tawarkan. Ingat, semua bisnis pesaing Anda juga sedang berusaha memberi solusi untuk permasalahan yang sama. 4) Market Size, selanjutnya adalah menunjukkan kepada calon investor seberapa besar pangsa pasar (market size) yang akan diraih lewat solusi yang Anda berikan. 5) Business Model, satu hal yang membedakan entrepreneur sejati dengan entrepreneur lainnya adalah mereka mampu menjelaskan bisnis model yang hendak dipakai. 6) Proprietary Tech, sebuah usaha yang menjanjikan memiliki keunggulan kompetitif. Keunggulan ini bisa berupa hak paten atas teknologi tertentu, cara pemasaran tertentu, pengalaman yang unik, ataupun penguasaan atas pangsa pasar; 7) Competition, jelaskan bagaimana peta persaingan yang ada. Semakin Anda mampu membuat pemetaan seperti ini, semakin kagum calon investor kepada Anda; 8) Marketing Plan, seorang investor akan tertarik dengan usaha yang memiliki rencana pemasaran yang jelas. Rencana ini mencakup bagaimana usaha Anda akan menjangkau konsumen; 9) Team, hal paling penting yang perlu Anda tunjukkan kepada venture capitalist (investor) tersebut adalah bagaimana tim tersebut saling berbagi peran dan bagaimana masing-masing anggota tim secara sinergis bergerak ke arah yang sama untuk memajukan perusahaan; 10) Money, ide boleh hebat, rencana boleh meyakinkan. Namun, seorang investor sejati baru akan tertarik jika Anda bisa menunjukkan penghasilan yang benar-benar diperoleh dari usaha tersebut.

Kegiatan pengabdian masyarakat ini memberikan nilai positif dan menambah ilmu pengetahuan bagaimana menyusun proposal bisnis yang baik dan 
bagaimana meningkatkan rasa percaya diri peserta dalam mempresentasikan proposalnya setelah tim abdimas memberikan pelatihan cara presentasi yang baik dan menarik. Kehadiran pelaksanaan pengabdian masyarakat ini dianggap sangat membawa manfaat bagi kelompok karang taruna maka kegiatan seperti ini diminta oleh ketua kelompok karang taruna untuk diadakan secara berkala dengan tema yang lebih menarik dan sesuai dengan perkembangan saat ini.

\section{SIMPULAN}

Dalam memberikan pelatihan penyusunan proposal bisnis yang baik, benar, dan menarik serta meningkatkan kemampuan dalam mempresentasikan proposal dengan cara yang menarik dengan waktu dan kondisi yang singkat dan tidak langsung bertatap muka dirasa kurang maksimal karena tidak bisa mengarahkan secara langsung (praktik) membuat proposal bisnis dan evaluasi menjadi kurang maksimal.

Peserta abdimas adalah penduduk usia angkatan kerja, mereka memiliki semangat dan sangat aktif di kelompok Karang Taruna Kelurahan Balekambang namun masih belum bisa mengembangkan kemampuan dalam berkomunikasi dengan pihak luar baik investor maupun pihak bank. Namun diharapkan ke depannya mereka bisa lebih mengasah kemampuan sehingga diharapkan dapat memiliki usaha dan menciptakan lapangan pekerjaan sendiri di lingkungannya.

Tim menyarankan agar pelatihan ini dapat dilakukan secara berkala. Hal ini diharapkan mampu menumbuhkan sumber daya manusia yang dapat mengembangkan usaha yang sudah ada, sehingga dapat memiliki usaha yang lebih besar dengan kepercayaan diri yang tinggi karena telah dibekali pengetahuan menyusun proposal dan mempresentasikannya.

\section{DAFTAR PUSTAKA}

Chrismardani, Y. (2014). Komunikasi Pemasaran Terpadu: Implementasi untuk UMKM. Jurnal NeO-Bis, 8(2). 176-189

Suprapto, H. A., Rusdi, M., \& Paryono. (2018). Pelatihan Pembuatan Proposal Rencana Bisnis (Business Plan) bagi Siswa Madrasah Tsanawiyah Nurul Hikmah dan SMP Al-Ikhsan guna Meningkatkan Kemampuan Berwirausaha. Jurnal Pengabdian Kepada Masyarakat (Abdimas): IKIP Siliwangi Volume 01 Nomor 02

Isnaini, S. (2009). Implementasi Komunikasi Pemasaran Terpadu sebagai Penyampai Pesan Promosi Usaha Kecil Menengah ( UKM ) di Indonesia. Masyarakat, Kebudayaan dan Politik, 22 (4), 324-332

Alifuddin M. \& Razak, M. (2015). Kewirausahaan: Strategi Membangun Kerajaan Bisnis. Jakarta: Magna Script Publishing

Hasyim, M. \& Nugrahanto, G. (2014). Pelatihan Pembuatan Proposal Kegiatan pada Remaja Dusun Ngepuh Lor Desa Banyusidi Pakis Magelang Jawa Tengah. Jurnal Inovasi dan Kewirausahaan. Volume 3 No. 3. Halaman 206-210

Setiawati, S. D., Purba, V., Retnasari, M., Fitriawati, D., \& Ngare, F. (2018). Membangun Kemampuan Presentasi Bisnis sebagai Upaya dalam 
KANGMAS: Karya Ilmiah Pengabdian Masyarakat, 1 (3), November 2020 - 106

http://journal.neolectura.com/index.php/Kangmas

Pengembangan Usaha Mikro Kecil Menengah. JURNAL ABDIMAS BSI:

Jurnal Pengabdian Kepada Masyarakat Vol. 1 No. 2. Hal. 252-258

Vol. 1, No. 3,

November

2020

pp. 100-106

e-ISSN:

2722-2004

Title

Training on

Preparing

Business

Proposals and

Effective

Communication

in Proposal

Presentations to

Karang Taruna

Balekambang,

East Jakarta

\section{Author}

K. Herwati,

I. Suyahya
Nooer, M. (Agustus 2013). Membuat Presentasi Proposal Usaha yang Meyakinkan Buat Entrepreneur. Presentasi.net. https://www.presentasi.net/proposalusaha-bisnis/

Niode, I. Y. (n.d.). Strategi Menyusun Proposal Bisnis yang Efektif. Disajikan pada mata kuliah Manajemen UKM. Slideplayer.info. https://slideplayer.info/slide/11870134/ 